\title{
EYCN: European Young Chemists Network
}

$>$

Carina I. C. Crucho

\begin{abstract}
European Young Chemists Network - EYCN. EYCN is the younger members division of the European Chemical Society (EuChemS), which is an umbrella organization representing national chemical societies from across Europe. EYCN is a motivated team of young scientists from 28 European countries, counting 40 official delegates (under the age of 35), representing and supporting more than 35.000 early career chemists across Europe. The EYCN aims to improve the visibility of chemistry and bring it closer to a wider audience and to people from outside the research field - including schools, partners in industry, business, and management. EYCN wants to provide development and networking opportunities to early career chemists across Europe and beyond. In the last years, more than 30 initiatives were coordinated or supported by the EYCN at a global level, in Europe and abroad. Among these, more than 20 conferences were sponsored and around 30 young chemists were awarded prizes for their outstanding scientific contributions. As young chemists, the EYCN priority is to enhance research collaboration where ideas and people can grow without limits and borders.
\end{abstract}

\begin{abstract}
A Rede Europeia de Químicos Jovens, EYCN, é a divisão de químicos jovens da Sociedade Europeia de Química (European Chemical Society - EuChemS), que é uma organização que representa as sociedades de química nacionais de toda a Europa. A EYCN é uma equipa motivada de jovens cientistas oriundos de 28 países europeus, contando com 40 delegados oficiais (com menos de 35 anos), representando e apoiando mais de 35.000 químicos em início de carreira em toda a Europa. A EYCN visa melhorar a visibilidade da química e aproximá-la de um público mais abrangente e de pessoas para além da academia - incluindo escolas, parceiros na indústria, negócios e administração. A EYCN quer oferecer oportunidades de desenvolvimento e networking para investigadores em início de carreira em toda a Europa e para além desta. Nos últimos anos, mais de 30 iniciativas foram coordenadas ou apoiadas pela EYCN a nível global. Entre elas, mais de 20 conferências foram patrocinadas e cerca de 30 químicos jovens receberam prémios pelas suas excelentes contribuições científicas. Como químicos jovens, a prioridade da EYCN é aumentar a colaboração na investigação, onde ideias e pessoas possam crescer sem limites e fronteiras.
\end{abstract}

\section{Connecting chemists across Europe \\ Lema da EYCN}

Oito jovens químicos entram num bar. Nada de estranho para quem quer pôr a conversa em dia acompanhado de um cocktail molecular, não estivesse a química por toda a parte. Tudo normal até aqui. No entanto, quando estes cientistas fazem parte da EYCN, em cima da mesa está sempre o futuro dos químicos jovens na Europa e todas as atividades desenvolvidas para promover a química como ciência central. 0 cenário poderia ser o ambiente descontraído de um bar, um auditório de uma faculdade, ou uma simples reunião via Skype, o que importa são as iniciativas que nascem sempre destes encontros e o entusiasmo que fica no ar de quem quer pô-las em prática.

\section{História}

A EYCN foi fundada em 2006 por dois químicos jovens, Jens Breffke e Csaba Janaky, durante o 1. ${ }^{\circ}$ Congresso Europeu de Química (European Chemistry Congress, ECC) em Budapeste. No ano seguinte, as Sociedades de Química Europeias foram convidadas a enviar os respetivos delegados a Berlim para a primeira assembleia de delegados (AD). Os dados estavam lançados, doze sociedades fizeram-se representar e a EYCN foi criada oficialmente. Desde então a EYCN continua a crescer, contando atualmente com trinta Sociedades de Química europeias, englobando 28 países e um membro afiliado, a Sociedade Americana de Química (ACS) (Figura 1). 


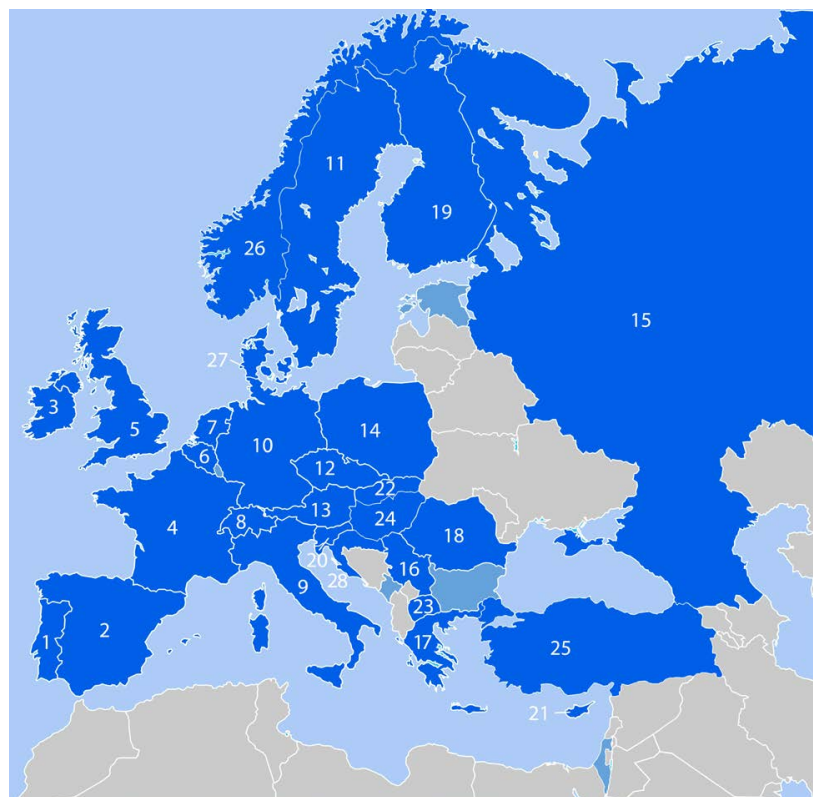

Figura 1 - Mapa de todos os países com delegados ativos na EYCN: (1) Portugal, (2) Espanha, (3) Irlanda, (4) França, (5) Reino Unido, (6) Bélgica, (7) Holanda, (8) Suíça, (9) Itália, (10) Alemanha, (11) Suécia, (12) Republica Checa, (13) Áustria, (14)

Polónia (15) Rússia, (16) Sérvia, (17) Grécia, (18) Roménia, (19)

Finlândia, (20) Eslovénia, (21) Chipre, (22) Eslováquia, (23)

República da Macedónia do Norte, (24) Hungria, (25) Turquia,

(26) Noruega, (27) Dinamarca, (28) Croácia.

\section{Organização}

A EYCN vive e prospera devido ao excelente trabalho de equipa de todos os seus membros. Os delegados são a voz da EYCN dentro de cada Sociedade Europeia. Sem a sua preciosa ajuda e divulgação dentro do seu próprio país, seria muito mais difícil tornar a EYCN uma rede cada vez mais internacional. Os delegados de cada sociedade estão organizados por cinco equipas com responsabilidades específicas: equipa de comunicação, equipa de conexões g'lobais, equipa de recrutamento, equipa de networking e equipa de ciência. Cada equipa é orientada por um líder, que juntamente com o Presidente, o Secretário, o Tesoureiro e o Conselheiro (o anterior Presidente da EYCN) formam o comité diretivo da EYCN. Atualmente o presidente da EYCN é Antonio M. Rodríguez (Espanha), assistido por Maximilian Menche (Alemanha), Carina Crucho (Portugal), Maxime Rossato (França), Lieke van Gijzel (Holanda), Miguel Steiner (Austria), Jovana V. Millic (Suiça) e Robert-Andrei Tincu (Roménia). A presidente anterior, Alice Soldà (Itália) apoia a direção como conselheira e faz parte do comité científico do 8. Congresso Europeu de Química (EuChemS Chemistry Congress) que iria decorrer em Lisboa em agosto de 2020, mas que foi adiado para 2022 por causa da pandemia COVID-19. Ao antigo presidente cabe a organização do simpósio EYCN durante o EuChems Chemistry Congress, totalmente focado nos interesses dos jovens químicos em início da carreira.
A análise estatística do perfil dos delegados da EYCN revela alguns dados curiosos. Atualmente a EYCN detém igualdade de género entre os seus membros, sem que para isso tenha sido implementado algum plano estratégico. A faixa etária situa-se maioritariamente entre os 26 e os 30 anos de idade e a maioria dos delegados são atualmente estudantes de doutoramento e investigadores pós-doutorais.

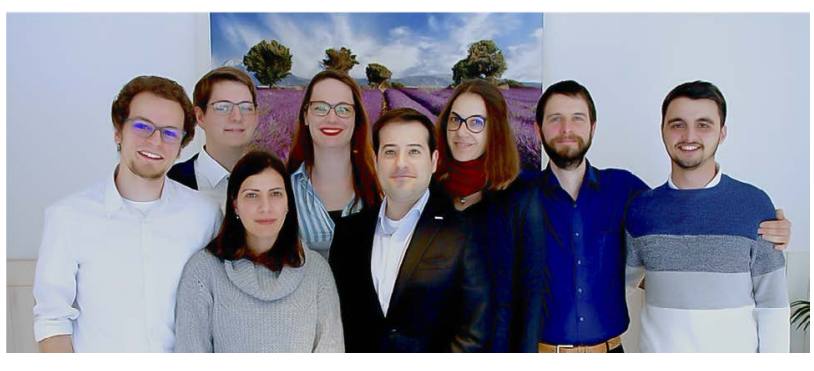

Figura 2 - Atual comité diretivo da EYCN. Da esquerda para a direita: Miguel Steiner (recrutamento), Maximilian Menche (secretário), Carina Crucho (tesoureira), Lieke van Gijzel (conexões globais), Antonio M. Rodríguez (presidente), Jovana V. Millic (networking), Maxime Rossato (comunicação) e RobertAndrei Tincu (ciência).

\section{Idade}

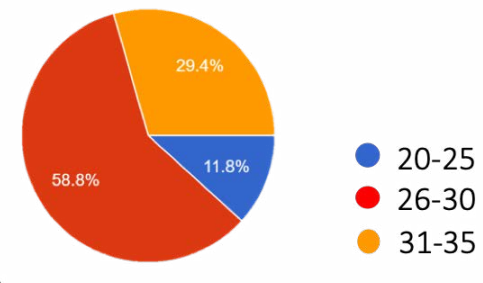

Ocupação

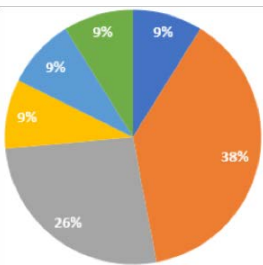

Estudantes de mestrado Indústria

- Estudantes de doutoramento Outros (ex. Institutos de

- Investigadores pós-doutorais investigação)

Professores

Figura 3 - Perfil estatístico dos delegados da EYCN.

\section{Atividades}

A EYCN é uma das divisões mais ativas da EuChemS e tem vindo a desenvolver uma série de atividades que têm como principal objetivo fomentar a interação e a divulgação científica entre a comunidade de químicos jovens europeus. As atividades desenvolvidas pela EYCN melhoram a visibilidade da química e conectam químicos jovens com parceiros na indústria e na academia. 


\subsection{Assembleia de delegados}

Todos os anos, a EYCN organiza um encontro com todos os representantes nacionais das respetivas sociedades, no qual o Grupo de Químicos Jovens (GQJ), com o apoio da Sociedade Portuguesa de Química (SPQ), se faz sempre representar. A agenda de cada Assembleia de Delegados (AD) é cuidadosamente planeada para que os tópicos incentivem os delegados a participar ativamente e a desenvolver novas ideias. Os projetos e atividades em andamento da EYCN pela Europa são apresentados pelo comité diretivo, assim como apresentações pelos próprios delegados sobre as atividades nas suas respetivas sociedades. A AD é também uma ocasião única para inúmeras sessões de trabalho em equipa, destinadas a preparar atividades futuras, com o intuito de maximizar o desempenho de cada equipa e incrementar a visibilidade da EYCN junto dos químicos jovens. Para além disso, grande parte do tempo da AD é destinado a palestras sobre soft skills, incluindo conselhos e orientações sobre a preparação de um currículo, como escrever um artigo científico, bem como oportunidades na indústria química e como funciona o processo de contratação.

\subsection{Prémios EYCN}

Como forma de incentivar a excelência entre os químicos jovens europeus, a EYCN coordena e atribui vários prémios. De todos, o mais importante é o Prémio Europeu de Químico Jovem - European Young Chemist Award (EYCA) - patrocinado pela Società Chimica Italiana e pelo Consglio Nazionale dei Chimici. O prémio, atribuído de dois em dois anos e entregue no Congresso Europeu de Química, consiste em três medalhas (uma de ouro e duas de prata), em duas categorias (doutoramento e pós-doc). Em parceria com o comité de químicos jovens da Sociedade Americana de Química, a EYCN também promove o programa de intercâmbio, Young Chemists Crossing Borders, que permite que os vencedores europeus viagem para o encontro nacional da ACS e os estudantes americanos participem no ECC. Para além disso, a EYCN apoia anualmente vários prémios de comunicação em painel em conferências. É fortemente incentivado o envio de projetos para os quais se deseja fazer uso dos recursos da EYCN.

\subsection{Chemistry Rediscovered}

O concurso bienal Chemistry Rediscovered é uma competição de vídeo destinada a estudantes do ensino secundário. À semelhança do concurso organizado anualmente pelo GQJ, ChemRus, consiste na realização de uma experiência científica com a ajuda de um professor e apresentar os resultados de forma criativa através de um vídeo, acompanhado por um protocolo experimental. 0 objetivo é promover a química entre os estudantes do ensino secundário de toda a Europa.

\subsection{Photochimica}

A EYCN também promove o concurso de fotografia científica, o Photochimica. 0 objetivo é estimular a visão e perceção sobre a importância da química em todos os aspetos da nossa vida. As doze melhores fotografias são posteriormente reunidas num calendário da EYCN. O GQJ também organiza um concurso semelhante, um Flash sobre a química. Aguarda-se ansiosamente as imagens captadas pelas objetivas dos químicos jovens portugueses para a próxima edição.

\subsection{Encontro europeu de jovens químicos}

A EYCN expandiu-se exponencialmente desde a sua fundação em 2006. Por esse motivo, e para comemorar o seu décimo aniversário, a EYCN enfrentou um dos seus maiores desafios: a organização do primeiro Encontro Europeu de Jovens Químicos (EYChem). Em 2016, o GQJ decidiu alargar o seu congresso, o Portuguese Young Chemists Meeting (PYChem) à comunidade de jovens químicos europeus, e realizou o 5. PYChem juntamente com 0 1. ${ }^{\circ}$ EYChem em Guimarães. 0 2. ${ }^{\circ}$ EYChem ocorreu em 2019 em Bremen, Alemanha, juntamente com o encontro nacional de jovens alemães, organizado pela Sociedade Alemã de Química (GDCh-JCF).

\subsection{Entrevistas EYCN}

Aprender com cientistas de renome mais experientes, ou sentir-se inspirado por jovens cientistas em ascensão, levou ao novo projeto realizado pela equipa de ciência: as Entrevistas da EYCN. Durante o 7. ECC, 30 grandes cientistas foram entrevistados, incluindo os laureados Nobel Prof. Ben Feringa (Sócio Honorário da SPQ desde 2018) e Prof. Frances H. Arnold, sem esquecer os químicos talentosos da nova geração. Horas de filmagens deram origem a pequenos vídeos com perguntas e respostas a temas atuais, como "Quais os desafios da química nos próximos anos?", ou a curiosidades científicas como: "Qual a sua reação química favorita?".

\section{Mascote}

Qualquer sociedade que se preze tem de ter uma mascote. Seja um talismã, algo que dá sorte, ou sirva de chamariz, também a EYCN tem a sua mascote oficial, a Prof. ${ }^{\text {a }}$ ChemChicken. A Prof. ${ }^{\text {a }}$ ChemChicken não dispensa a sua bata de laboratório decorada com vários pins de referência. Viajando pelo mundo todo, a infatigável galinha tem representado a EYCN em incontáveis encontros internacionais. De mão em mão, todos querem uma selfie com a Prof. ${ }^{a}$ ChemChicken e no livro das suas memórias já contam várias fotos, incluindo com aclamados prémios Nobel. 


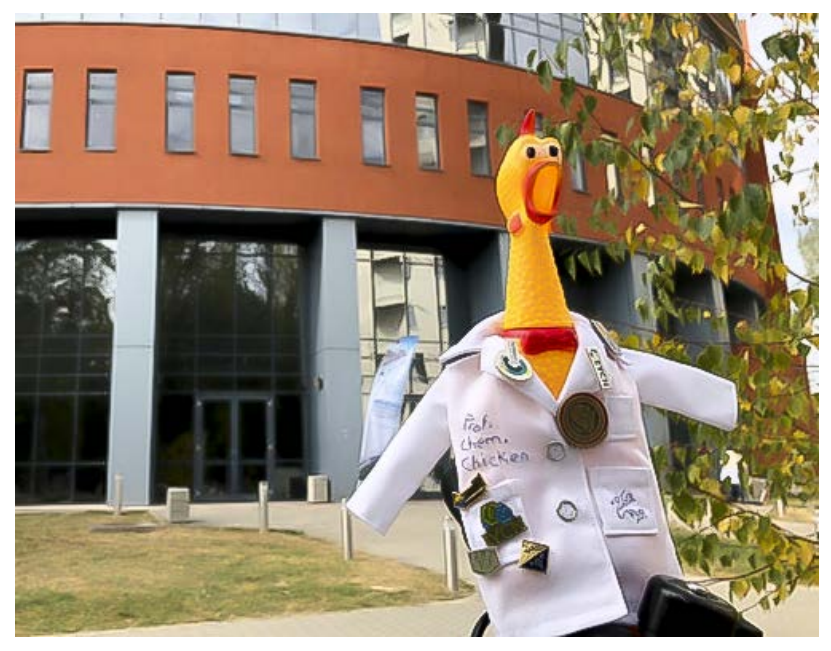

\section{Conclusão}

A EYCN tem vindo a crescer com o apoio imprescindível da EuChemS, que faz questão de estar sempre presente durante as assembleias de delegados. Estas tornam-se imprescindíveis para a partilha de conhecimentos e atividades entre as várias sociedades. Por isso, é comum a realização das mesmas atividades em vários países. As Sociedades mais recentes acabam por se inspirar nas atividades levadas a cabo pelas mais experientes. É importante ressalvar que qualquer membro de uma Sociedades que pertença ao EuChemS, como por exemplo a SPQ, e que tenha menos de 35 anos, pertence automaticamente à EYCN. A EYCN pretende continuar a trabalhar para estabelecer novas parcerias
Figura 4 - A mascote da EYCN, a Prof. - ChemChicken. com as principais indústrias e sociedades da Europa e para além desta.

Como surgiu a vida? 0 que existe para lá do Universo? São alguns dos grandes mistérios da humanidade. Talvez à química lhe falte a grande questão. No entanto, como ciência central e estando presente em toda a parte, inúmeras questões não lhe faltam. Agora, cabe a todos nós promovê-la da melhor maneira.

\section{Agradecimentos}

Carina Crucho agradece ao comité científico da EYCN e a todos os delegados pelas imagens e informação sobre a EYCN, incluindo os dados estatísticos.

\section{Referências}

[1] European Young Chemists Network team, Introducing the European Young Chemist Network, ChemistryViews.org, outubro, 2012. DOI: 10.1002/chemv.201200122.

[2] F. Gomollón-Bel, C. Oger, C. Todasca, EYCN: Ten Years Connecting Young Chemists, ChemistryViews.org, Setembro, 2015, DOI: 10.1002/ chemv.201500500.

[3] EuChemS. European Young Chemists' Network: eycn.eu (acedido em: 29/02/2020).

\section{$>$}

\section{Carina I. C. Crucho}

É doutorada em química pela FCT - Universidade Nova de Lisboa e atualmente é investigadora júnior no Instituto de Bioengenharia e Biociências do Instituto Superior Técnico. Os interesses de investigação têm incidido sobretudo no desenvolvimento de nanomateriais para aplicações biomédicas.

carina.crucho@tecnico.ulisboa.pt ORCID.org/0000-0002-6361-2800 